IZA DP No. 6992

Do Low-Wage Workers React Less to

Longer Unemployment Benefits?

Quasi-Experimental Evidence

Mário Centeno

Álvaro A. Novo

November 2012 


\title{
Do Low-Wage Workers React Less to Longer Unemployment Benefits? Quasi-Experimental Evidence
}

\author{
Mário Centeno \\ Banco de Portugal, \\ ISEG, Universidade Técnica de Lisboa and IZA \\ Álvaro A. Novo \\ Banco de Portugal, \\ Universidade Lusófona and IZA
}

Discussion Paper No. 6992

November 2012

\author{
IZA \\ P.O. Box 7240 \\ 53072 Bonn \\ Germany \\ Phone: +49-228-3894-0 \\ Fax: +49-228-3894-180 \\ E-mail: iza@iza.org
}

Any opinions expressed here are those of the author(s) and not those of IZA. Research published in this series may include views on policy, but the institute itself takes no institutional policy positions. The IZA research network is committed to the IZA Guiding Principles of Research Integrity.

The Institute for the Study of Labor (IZA) in Bonn is a local and virtual international research center and a place of communication between science, politics and business. IZA is an independent nonprofit organization supported by Deutsche Post Foundation. The center is associated with the University of Bonn and offers a stimulating research environment through its international network, workshops and conferences, data service, project support, research visits and doctoral program. IZA engages in (i) original and internationally competitive research in all fields of labor economics, (ii) development of policy concepts, and (iii) dissemination of research results and concepts to the interested public.

IZA Discussion Papers often represent preliminary work and are circulated to encourage discussion. Citation of such a paper should account for its provisional character. A revised version may be available directly from the author. 
IZA Discussion Paper No. 6992

November 2012

\section{ABSTRACT}

\section{Do Low-Wage Workers React Less to Longer Unemployment Benefits? Quasi-Experimental Evidence}

The fact that unemployed workers have different abilities to smooth consumption entails heterogeneous responses to extended unemployment benefits. Our empirical exercise explores a quasi-experimental setting generated by an increase in the benefits entitlement period. The results point towards a hump-shape response of unemployment duration over the one-year pre-unemployment wage distribution; individuals at the bottom and at the top of the wage distribution reacted less than those in the interquartile range. This behavior of job searchers is consistent with labor supply models with unemployment insurance and savings. It questions the optimality of very long entitlement periods to target the unemployment experiences of low-wage workers.

JEL Classification: J65, J64, J22

Keywords: unemployment insurance, unemployment duration, entitlement extension, liquidity effect

Corresponding author:

Álvaro A. Novo

Banco de Portugal

Av. Almirante Reis, 71-6DEE

1150 Lisboa

Portugal

E-mail: anovo@bportugal.pt

\footnotetext{
* We are grateful to Patricia Anderson, David Margolis, Bas van der Klaauw, and seminar participants at the EEA Meeting, Milan, the AIEL Meeting, Brescia, and the SOLE Meeting, Boston. We acknowledge the financial support provided by FCT grant PTDC/ECO/64398/2006. We would like to thank the Instituto de Informática (II) of the Portuguese Social Security bureau for making the data available to us. Opinions expressed herein do not necessarily reflect the views of Banco de Portugal and $I I$.
} 


\section{Introduction}

Does one month of extended unemployment insurance (UI) benefits affect individuals behavior equally? The answer to this simple question has important implications for the design of optimal UI policies. Even if it has been recognized for quite a long time that the response to the benefits is better understood in a heterogeneous environment (see Mortensen 1986, for a survey of seminal work), only recently did the labor economics literature started paying more attention to these issues, of which Gruber (1997), Card, Chetty \& Weber (2007a) and Chetty (2008) are leading examples. Our empirical exercise explores a quasi-experimental setting generated by an increase of the UI entitlement period. The key result of the paper extends this literature by showing that the extension induced an hump-shaped response over the one-year pre-unemployment wages distribution, with unemployment duration increasing the least for low-wage individuals. These results are consistent with a general job search model with UI and savings.

The job search models of Lentz \& Tranæs (2005) and Card et al. (2007a) show that, under incomplete insurance markets, the impact of an UI extension on the ability to smooth consumption depends on the level of savings, through their influence on the level of consumption and on the job search effort. The model with UI predicts that the impact on unemployment duration of a benefit extension operates through two channels. One channel takes into account the impact on the marginal utility of consumption, extending unemployment duration due to an increased ability to smooth consumption. The other channel takes into account the probability that the individual remains unemployed until the date in which the benefit extension accrues. The response to the incentives will be stronger for individuals that combine a large probability of reaching the extension period with a low ability to smooth consumption. The empirical implications of these propositions are at the core of our exercise and are the main novelty of the paper.

In the empirical identification of the UI causal effect, we explore a quasi-experimental setting generated by the July 1999 reform of the Portuguese UI system. The reform increased the entitlement period from 15 to 18 months for all individuals aged 30-34 years, a natural treatment group for our evaluation. For the contiguous age group, 35-39, the entitlement period was left unchanged at 18 months, and we will use it as the control group. These features result in a privileged quasi-experimental setting, which is reinforced by the economic relevance of the groups studied, composed of prime-age individuals, and also because, after the reform, the 
treatment and control groups have the same entitlement periods. In addition, the good economic conditions prevailing at the moment of the reform are favorable to the empirical identification, as the policy change was not motivated endogenously by the labor market conditions of specific groups favored by the extension (Card \& Levine 2000).

We use Social Security administrative data covering the whole population of subsidized unemployed workers, and show that the extension of UI benefits increased subsidized unemployment duration. This result fails to reject a model with forward looking agents. As predicted by theory, we also find that the impact is stronger as the duration of unemployment approaches the extension period.

The core of the paper analyzes the impact on unemployment duration of extended benefits for different levels of one-year pre-unemployment wages, which proxy the ability to smooth consumption over labor market states. We find that the two channels identified in the model are key to explain the heterogeneous reactions to the policy incentive. First, individuals with ex-ante lower probability of exhausting UI in the pre-reform system, and therefore less likely to reach the extension, react the least. In the data, these are typically low-income workers, a result in line with the evidence in Stancanelli (1999), Bloemen \& Stancanelli (2001) and Algan, Chéron, Hairault \& Langot (2003). Second, for individuals with accumulated wages above the first quartile, who have similar ex-ante probabilities of exhausting the benefits, the results show that those with higher wages reacted less to the extension. A result consistent with a liquidity effect of UI. Chetty (2008) pointed out that UI triggers not only a substitution effect (moral hazard), but also a liquidity effect. The latter arises from the fact that individuals face different liquidity constraints while unemployed and, therefore, value consumption (smoothing) differently. Overall, these responses yield a hump-shaped relation with one-year pre-unemployment wages.

These results extend a still sparse literature on the liquidity effect of UI. They tell us that the population of unemployed workers is quite heterogeneous. In Chetty (2008), most of the reaction to a more generous UI is concentrated on workers proxied as liquidity constrained. In our case, the most interesting behavior is also observed among such workers. Although more UI has a larger marginal impact on consumption among constrained workers, these are also the least capable of remaining unemployed until the UI extension occurs, which reduces their scope to react to an UI extension. 


\section{Job search model: UI and consumption smoothing}

The main theoretical results that motivate the empirical exercise in this paper are derived from the work of Lentz \& Tranæs (2005) and Card et al. (2007a). At the core of these models is the fact that unemployed agents use the income from UI and from the period prior to unemployment to smooth consumption during the job search period. The magnitude of the reaction to an increase in the UI entitlement period depends on the extent to which individuals can smooth income fluctuations on their own during the jobless period. In this brief exposition, we follow primarily Card et al. (2007a), who discuss explicitly the impact on job search of changes to the entitlement period of UI.

In the model, the unemployed worker maximizes the expected value of entering period $t$ without a job and with total assets $A_{t}, J_{t}\left(A_{t}\right)$. Search intensity, $s_{t}$, is normalized to equal the probability of finding a job in the current period and is chosen to solve:

$$
J_{t}\left(A_{t}\right)=\max _{s_{t}} s_{t} V_{t}\left(A_{t}\right)+\left(1-s_{t}\right) U_{t}\left(A_{t}\right)-e\left(s_{t}\right)
$$

where $U(\cdot)$ is the value function of remaining jobless in period $t, V(\cdot)$ is the value function of getting a job in that period and $e(\cdot)$ is a convex search cost function.

The value functions of employment and unemployment reflect the consumption decisions, given total assets at the beginning of the period and the income flow during that period. If unemployed, an individual receives UI worth $b_{t}$, and sets consumption equal to $c_{t}^{u}$ for a value function:

$$
U_{t}\left(A_{t}\right)=\max _{A_{t+1} \geq L} u\left(A_{t}-\frac{A_{t+1}}{1+r}+b_{t}\right)+\frac{1}{1+\rho} J_{t+1}\left(A_{t+1}\right)
$$

where $r$ is an interest rate and $\rho$ is a discount rate. $L$ is a lower-bound on assets that may or may not be binding and $u(\cdot)$ is a concave utility function. Similarly, we could write the value function of employment, $V(\cdot)$, with the flow utility in each period defined as a function of the wage rate. Referring to Card et al. (2007a) for the details, the first order condition of problem (1) equalizes the marginal costs of search to the marginal benefit of employment, computed as the difference between the value functions of the employment and unemployment states, and is given by $V_{t}\left(A_{t}\right)-U_{t}\left(A_{t}\right)=e^{\prime}\left(s_{t}\right)$.

From the optimal solution, Card et al. (2007a) derive the impact on search intensity in the 
current period, $s_{t}$, of a change in future benefits, $b_{t+j}$ :

$$
\partial s_{t}^{*} / \partial b_{t+j}=-p_{t, j}^{*} \frac{E_{t}\left[u^{\prime}\left(c_{t+j}^{u}\right)\right]}{(1+\rho)^{j} e^{\prime \prime}\left(s_{t}^{*}\right)} \leq 0, \quad \text { where } p_{t, j}^{*}=\prod_{i=1}^{j}\left(1-s_{t+i}^{*}\right) .
$$

The $p_{t, j}^{*}$ term is the probability that an individual is still unemployed in period $t+j$, given that the worker was unemployed at $t$, i.e., it is the survival rate at $t+j$. As it is standard in this literature, the model predicts that an increase in UI benefits reduces search effort, increasing unemployment duration. The distinct feature is that the impact comes about through two channels. First, through the probability that an individual remains unemployed up to the benefit extension, $p_{t, j}^{*}$. Second, through the impact on the expected marginal utility of consumption while unemployed, net of search costs. For convenience, we will refer to the first as the survival channel and the second as the consumption channel.

In the empirical section, while testing the result of equation (3), we will explore primarily the heterogeneity that arises in the model due to differences in the individuals' ability to smooth consumption over labor market states. This heterogeneity is captured by the difference in marginal utilities while employed and unemployed, which, as shown in the first order condition, depends on the level of assets. Unconstrained individuals have a small difference in the marginal utilities of consumption, $\Delta=u^{\prime}\left(c_{t}^{e}\right)-u^{\prime}\left(c_{t}^{u}\right) \simeq 0$. They are able to smooth consumption without UI and, therefore, will react the least to longer UI entitlement periods.

Figure 1 illustrates the effect of the benefit extension on job search intensity for different initial levels of assets and over the duration of the unemployment spell, separating the total effect expressed in equation (3) into the survival and consumption channels.

[FIGURE 1; see page 27]

Proposition 2 of Lentz \& Tranæs (2005) is useful to motivate the effect of the survival channel. It shows that individuals with more assets $\left(A^{H}\right)$ have lower search levels, implying higher probabilities of reaching the extension period, $p_{t, j}^{*}$. This is shown in the left panel of Figure 1, after taking into account the reaction to the change in UI entitlement. At the beginning of the unemployment spell search levels are similar across asset levels. But as the spell progresses, constrained workers (with less assets, $A^{L}$ ) are less able to retain pre-unemployment consumption levels. This leads to an increase in search intensity and to lower survival rates in unemployment. Stancanelli (1999) and Algan et al. (2003) present empirical evidence that 
richer workers (their proxy for unconstrained workers) stay unemployed longer. In the empirical section, we present evidence consistent with these results for the Portuguese labor market.

The longer job search spells of unconstrained workers are associated with their higher ability to adjust to temporary income shocks. Because of this, they exhibit lower variation in the marginal utility of consumption while unemployed and, consequently, will react less to an increase in the UI entitlement period. This is shown in the middle panel of Figure 1: constrained individuals $\left(A^{L}\right)$ have a larger change in search intensity due to a higher marginal utility of consumption. The effect is increasing with elapsed duration; workers become increasingly constrained and, therefore, marginally more reactive to the benefit extension.

The combined effect of the two channels implies a fall in job search intensity, but the relative magnitude for different degrees of constraints is ambiguous. The right panel of Figure 1 shows one instance where individuals with an intermediate level of assets $\left(A^{h}\right)$ react the most at longer durations. More constrained individuals, despite their high marginal utility of consumption, may react the least to the UI extension because of the survival channel. At long durations, we obtain a hump-shaped relationship between the change in search intensity and the ability to smooth consumption. This is the question at the core of our empirical exercise.

\section{The UI reform and the economy}

\section{The extension of some entitlement periods}

One peculiar feature of the Portuguese UI system, prevailing at the time of the reform, was the definition of the entitlement period. Previous social security contributions determined only eligibility and the value of the benefits, but not the duration of the UI coverage. The UI length was fully determined by the individual's age at the beginning of the unemployment spell. The law defined eight entitlement levels corresponding to eight age groups (Table 1).

In July 1999, a reform increased the entitlement period for six of the eight age groups and reduced the number of groups to four, with some contiguous age groups now sharing the same entitlement. In particular, the reform increased the entitlement from 15 to 18 months for all individuals aged 30-34 years, a natural treatment group for our evaluation. For the contiguous age group, 35-39, the entitlement was left unchanged at 18 months, and we will use it as the control group. The new rules applied only to new UI claimers; all ongoing subsidized unemployment spells kept the same entitlement period as defined in the old legislation. 
[TABLE 1; see page 23]

One of the main advantages of this pair of age groups is the fact that after the reform they share exactly the same entitlement period, 18 months. Additionally, given age proximity, the treatment and the control groups are likely to share similar labor market characteristics, for instance, in terms of labor income and decisions regarding schooling, marital status, and child-bearing.

We could also use the $[15,24]$ and $[25,29]$ age groups as treatment and control; the entitlement period increased to 12 months for the younger group, but remained unchanged for the older one. We decided against it because the treatment group would be composed of rather young individuals, 15 to 24 years old, with low labor market attachment (for whom, for instance, educational and marital choices are still central). More importantly, we should note that the income distribution of those aged 15 to 24 has a small region of common support with the older control group, 25-29 (and the remaining population). As an alternative to test the robustness of our results we will use the $[40,44]$ age group as treatment and the $[35,39]$ as control group. ${ }^{1}$

\section{Economic conditions}

At the moment of the reform, the Portuguese economy and labor market were buoyant (Table 2). In the period just prior to the reform, real GDP growth exceeded 4 percent and employment was growing consistently above 2 percent. The unemployment rate was at or below 5 percent, showing signs of a tight labor market situation.

[TABLE 2; see page 23]

Like others have emphasized (e.g. Card \& Levine 2000), good economic conditions are favorable to the empirical strategy. They suggest that the policy change was not driven endogenously by the evolution of the labor market. In particular, it is reassuring that there is no difference in the pre-reform trends of the unemployment rate of the treatment and control groups (Figure 2). Instead, there are two exogenous factors that help understand the motivation of the reform. First, in the event of joining the euro area monetary union, the Portuguese public finances benefited significantly from falling interest rates; interest payments decreased from $8.1 \%$ of GDP,

\footnotetext{
${ }^{1}$ The possibility of extending the analysis to workers with more than 44 years is hindered by three factors: (i) there are no obvious control groups, i.e., the entitlement periods changed for all older individuals; (ii) in the after period, the entitlement period became a function of previous social contributions, which are unknown to us in the data; and (iii) the same legislative change introduced generous early retirement schemes for older $(+50$ years) unemployed workers, which severely confound the identification of the UI extension impact.
} 
in 1992, to $3.0 \%$, in 1999. Part of this budgetary slack was used to expand social and labor market programs. Second, the political cycle may have played also a role because there were scheduled elections for the second half of 1999.

[FIGURE 2; see page 27]

Furthermore, the treatment and control groups, composed of prime-age workers, usually suffer less with labor market swings than younger workers and do not face the type of retirement decisions common to older workers. This makes our comparison of pre- and post-reform outcomes more convincing, as it is not driven by a specific trend in the labor market or to questions related with population ageing.

\section{Data}

Our study uses administrative data collected by the Portuguese Social Security Bureau. The dataset recorded all subsidized unemployment spells initiated between January 1, 1998 and June 30,2003 , which amount to 232,225 new UI claims; the flow of initial claims made by the age group [30,39] ascended to 62,547 . The dataset contains very detailed and reliable information on the type, amount, and duration of benefits. The socio-demographic variables available are limited to gender, age, and place of residence. We also have information on wage income prior to unemployment. This comes from the record of wages that determines eligibility and the benefit value. To be eligible, workers needed to have at least 18 months of registered wages in the 24-month period preceding unemployment. Then, the benefit value is based on the average of the wages earned over the months worked in the 12-month period that precedes unemployment by two months. This avoids wage manipulation in the last (two) months of employment to obtain higher benefits and measures the stream of labor income accumulated over one year.

We study periods of subsidized unemployment, without distinguishing between competing exit destinations - reemployment or non-employment. From a statistical point of view, it is important to notice that we are able to observe the complete subsidized spell. This corresponds to a single-cycle/flow sampling scheme as defined in Lancaster (1992). Table 3 contains descriptive summary statistics of the key variables before and after the reform.

[TABLE 3; see page 24]

The treatment group comprises 34,953 observations, of which 4,780 are from the period 
before July, 1999. The control group has 5,160 observations in the before period and 22,434 in the after period. The differences in the 12-month average values of real pre-unemployment wages between treatment and control groups are minor, but, as expected, wages are higher for older individuals. The percentage of women is also similar across treatment and control groups, although it increases in the after period. The fact that both the percentage of women and wages increases in the younger group (treatment) in the after period is in part due to the increasing participation of women in the labor market, who are also exceedingly more educated than men. ${ }^{2}$ Like unemployment itself, benefit claims have a slight seasonal pattern.

The gross replacement ratio hovers around 69 percent. But the UI rules generate a substantial degree of heterogeneity in the replacement rates with respect to the pre-unemployment wages. The system considered three levels of the 12-month average pre-unemployment wages to determine the value of the UI benefit. First, for wages between one and 1.5 minimum wages, the benefit equaled one minimum wage. Second, for those with wages between 1.5 and 4.5 minimum wages, the gross replacement rate was $65 \%$. Finally, those earning more than 4.5 minimum wages were entitled to a benefit worth 3 minimum wages. Workers who earned less than 1.5 minimum wages represent $32 \%$ of the subsidized unemployed, while $5.9 \%$ earned more than 4.5 minimum wages. The vast majority of workers falls in the wage range with the constant gross replacement rate. These rules resulted in a non-linear relationship between benefits and wages - with gross replacement in the data ranging from $100 \%$ to $11.1 \%$ - that will help disentangle varying moral hazard effects in the estimation.

Overall, despite the fact that these are summary statistics for the raw data, covariates are well balanced across the groups. These are also reassuring that there is common support between the groups and that, after using suitable regression methods (or matching), they will be appropriately balanced (Angrist \& Pischke 2009).

\section{Causal inference on the UI extension}

This section presents the quasi-experimental estimates of the impact on the duration of subsidized unemployment of an UI extension. We use a set of proportional hazard models and perform several robustness checks of the identification strategy.

\footnotetext{
${ }^{2}$ According to Labor Force Survey data, between the first quarter of 1998 and the second quarter of 2003, women's participation increased by 3 percentage points, while men's labor market participation increased only 0.7 percentage points. In 1998 , there were 72,000 more women with a college degree than men, but the gap widened to 122,000 more women in 2003.
} 


\subsection{The treatment effect}

We start with an empirical identification based on the estimation of a stratified version of the proportional hazard model for unemployment exits. The hazard function represents the probability of unemployment termination conditional on the duration lasting up to $t$, formally:

$$
\lambda^{k}(t \mid x)=\lambda_{0}^{k}(t) \exp (x \alpha)
$$

where $k$ refers to one of the four pairs that result from combining the treatment status (control and treatment groups) with the time periods (before and after). The $x$ vector includes dummy variables and continuous demeaned individual characteristics, namely, individual's age at the beginning of the unemployment spell; ( $\log ) 12$-month average of pre-unemployment wages; gross replacement rate; a gender (female) indicator; regional (22 districts) dummies; and month of unemployment entry dummies. In this case $\lambda_{0}^{k}(t)$ is the baseline hazard rate at time $t$ for the covariate vector $x=0$ for a given pair $k$. The estimation of $\alpha$ is based on the standard Cox (1972) semi-parametric estimator. The associated baseline hazard estimates, $\lambda_{0}^{k}$, are obtained non-parametrically with the product limit estimator (Kalbfleisch \& Prentice 2002).

An important characteristic of this approach is the flexibility of the baseline hazard over the four pairs defined above. The treatment effect is captured by the differences in the nonparametric baseline hazards specific to each pair, as in a difference-in-differences approach.

Figure 3 plots these survival curves for a reference person and, at the bottom of the figure, the difference-in-differences estimates at each unemployment duration. This curve lends support to an increasing impact of an UI extension on the duration of subsidized unemployment, the delayed effect. Similar results are found for Austria and Finland by Lalive, van Ours \& Zweimueller (2006) and Kyyra \& Wilke (2007), respectively.

[FIGURE 3; see page 28]

Figure 3 illustrates also that the magnitude of the impact is primarily driven by the significant upward shift in the survival curve of the treatment group. Concurrently, it accounts for the quality of the quasi-experimental setting. As expected, it is clear that the survival curve for a reference unemployed of the control group did not change much across periods; the slight downward movement is fully compatible with the better position of the economic cycle in the after period. We take this as evidence that reinforces our case for an exogenously driven reform. 
Furthermore, after the reform, when the entitlement periods are the same for the treatment and control groups, the survival curves for reference individuals of both groups are closer.

As an alternative approach, we follow the traditional difference-in-differences literature and estimate a common survival model with treatment status indicators:

$$
\lambda(t \mid X)=\lambda_{0}(t) \exp \left\{\beta_{0}+\beta_{1} \text { After }+\beta_{2} \text { Treat }+\beta_{3} \text { After } \times \text { Treat }+x \alpha\right\},
$$

where After is an indicator variable for the period after the reform, Treat indicates the agegroup affected by the new legislation, and, therefore, the coefficient on After $\times$ Treat identifies the treatment effect for a given reference individual. The vector $x$ is as defined above. Note that this formulation imposes a common baseline, $\lambda_{0}$, but we gain in terms of a statistical formulation that makes inference easier. Subsidized unemployment durations are censored at 450 days, which is the common entitlement period for the treatment and control groups in both periods. The coefficients can be interpreted as changes in the subsidized unemployment hazard rate over the first 450 days of the spell.

The basic result confirms the analysis from Figure 3, namely, that the policy induced significantly longer unemployment spells (Table 4, column (1)). The negative coefficient, -0.492 , of the After $\times$ Treat variable implies a sizable reduction in the hazard rate of subsidized unemployment due to the UI extension. The reform made individuals in the treatment group 39 percent less likely to leave unemployment in a given month relatively to the counterfactual with shorter UI. This impact is computed over the range of subsidized unemployment durations that is common to both the extended and the former UI regime, that is, up to the pre-reform entitlement period for the treatment group, 450 days. Thus, the estimated impact should be interpreted as a truly behavioral response, and not as a simple mechanical effect due to a longer entitlement period. ${ }^{3}$

[TABLE 4; see page 25]

To illustrate the size of the effect, we compute the value of the survival function for a particular set of covariates. In the absence of changes in the law, a 32-year-old man with an

\footnotetext{
${ }^{3}$ Card, Chetty \& Weber $(2007 b)$ show that the hazard rate of "registered unemployment at the UI exhaustion date" is bigger than the hazard rate for the stochastic process measuring "time to next job." More relevant to our application, they also show that the impact of a longer entitlement period on the hazard rates of both unemployment duration measures is approximately the same (minus 6 percent in their case). In our case, the estimates of the impact are also not sensitive to the choice of the unemployment duration measure. When we measure unemployment duration as the "time to next job", the estimate for the After $\times$ Treat variable is -0.454 , with a $t$-statistic of -18.04 . This compares with -0.492 in Table 4.
} 
average pre-unemployment wage would have a 53 (83) percent chance of exiting UI in the first 6 (12) months. After the reform, the same probability falls to 41 (74) percent, a shift of around 10 percentage points at both durations.

The size of this effect is consistent with recent estimates for Portugal and other economies. The strong responsiveness of Portuguese unemployed workers to the UI entitlement period is confirmed in Addison \& Portugal (2008) using survey data in a regression discontinuity setup; an increase in the benefits of also three months reduces the escape rate by 70 percent. Addison, Centeno \& Portugal (2010) also show that Portugal has one of the largest elasticities of unemployment duration with respect to the UI replacement rate (the Portuguese elasticity is 0.390, which compares with an average of 0.247 for 12 countries in the European Union Household Panel sample). The evidence on the effect of the benefit extensions in European countries is mixed. Hunt (1995) points to a large impact in Germany. For a 6-month increase in the entitlement period, her estimates show a reduction of 46 percent in the hazard of unemployment for individuals aged 44 to 48 years old. Hunt (1995) estimates that 47-year-old married male with apprenticeship degree would have a 55 percent chance of finding a job in the first 6 months before the UI extension and this would fall to 35 percent after the law change. Also for Germany, Fitzenberger \& Wilke (2010) report noticeable effects on exits from unemployment for entitlement lengths above 12 months, in contrast with weak effects for smaller entitlements. In a more recent paper, van Ours \& Vodopivec (2006) also report a sizeable impact on unemployment duration of a reduction in the entitlement period in Slovenia. For a 40 years old, the cumulative probability of leaving unemployment after 6 (12) months increases from $42(63)$ percent to 57 (77) percent when the entitlement period is reduced from 12 to 6 months. Several studies for the Austrian labor market report smaller effects, for example Lalive et al. (2006) and Card et al. (2007b). However, when Lalive et al. (2006) restrict the sample to a younger age group the estimates of the impact of extended benefits are three times larger than their baseline estimates. This finding is consistent with other studies that find smaller effects for older workers, as first pointed out in Narendranathan, Nickell \& Stern (1985).

These results provide clear evidence that the unemployed reacted to the extension of the benefits. They display forward looking behavior, taking into account the future expected income provided by the UI extension. Next, we use this setup to test the main results of the theoretical framework laid out above. 


\subsection{The heterogeneous take up of extended benefits}

\section{Definition of heterogeneous groups}

The job search model discussed above highlights the importance of savings and the ability to smooth consumption in determining search outcomes. In the literature, in the absence of direct observations of labor supply and consumption decisions, many variables have been used to proxy consumption smoothing (Chetty 2008, p. 195). To proxy the ability of workers to smooth consumption intertemporally, we resort to the information on the stream of labor income over the one-year period that precedes unemployment. In the empirical exercise, as in Figure 1, we will consider three distinct groups based on this income measure: (i) the first quartile, (ii) the interquartile range, and (iii) the top quartile. The interquartile range includes average monthly wages ranging from 463 to 888 euros, at 1999 prices, when the minimum wage was 306 euros.

Wages earned in the year prior to unemployment can be seen as a good predictor of the ability to smooth consumption while unemployed. They capture recent labor market stability and labor income flows, which are the two main mechanisms used by salaried workers to accumulate savings. This measure of the average labor income earned over a year works to our advantage to capture the financial constraints at the moment of job loss. A simple example makes this point clear. An individual, who worked 6 months in the year before became unemployed and earned 1000 euros per month, has a 500 euros annual average wage. Another worker, who earned exactly 500 euros each month and worked the full year, would have accumulated the same labor income. This measure assigns appropriately the same degree of liquidity constraints to both workers; but if we had used the last wage earned, the former would be classified as unconstrained, an unlikely event for someone who worked 6 months in a year. The usage of labor income is not novel in this context. Card et al. (2007a) and Chetty (2008) also use measures based on wages as indicators of the constrained status to test the implications of UI on job search outcomes.

Other measures have been proposed in the literature, such as measures of accumulated financial assets, mortgages, and household total labor supply. However, as pointed out in Chetty (2008), these variables may capture saving behaviors that may be unrelated with labor market fluctuations, such as education or health motifs, and workers may not be willing to use them to finance job search. On the contrary, especially among low-wage workers, the ability to smooth consumption will be highly associated with their capacity to self-finance future layoffs 
and their recent labor market experience, both in terms of employment stability and wages earned.

Additionally, Ziliak (2003) corroborates that labor-market income is the leading factor in explaining the gap between rich and poor in terms of the ratio of net worth to permanent income. We can assess the quality of pre-unemployment wages as an index for the distribution of financial wealth in the Portuguese economy with the 2000 Household Wealth Survey data. In the survey, agents with low wages (1st quartile) hold financial assets worth only 2.9 times their median wage, interquartile range wage earners hold assets worth 4.3 times their median wage, and top wage earners 7.6 their median wage.

Nevertheless, wages have two shortcomings as a proxy for the ability to smooth consumption. First, wages are a temporary source of income, which may not be available to smooth consumption at the moment of unemployment. This may lead to misclassifying as unconstrained individuals with difficulties to smooth consumption. If that is the case, the estimates of the reactions of the two groups - constrained and unconstrained - will be closer. Second, even if wages were a perfect measure, the choice of the threshold to distinguish constrained and unconstrained individuals is somewhat fuzzy. The inclusion of unconstrained individuals in the group of constrained individuals (1st quartile) will artificially result in more similar estimates of the impact in the two groups. The opposite misclassification will also tend to equalize the estimates across the different constrained groups. Overall, this leads to the conclusion that the use of labor income as a proxy for constraints will result, if anything, in an underestimate of the true differences between constrained and unconstrained workers.

\section{Differentiated impacts on unemployment duration}

We start by substituting in equation (5) dummy variables that identify the wage groups defined above for the $(\log )$ pre-unemployment wages. The impact of this change is minor; the treatment effect increases from -0.49 to -0.46 (Table 4, column (2)). However, in order to test the differentiated impacts of the UI extension in the three wage groups, we have to interact the treatment indicators (Treat, After, After $\times$ Treat) with the dummy variables that identify each group. Column (3) of Table 4 presents the results.

The parameters of interest are now those associated with the variables: After $\times$ Treat, After $\times$ Treat $\times$ Interquartile Wages, and After $\times$ Treat $\times$ Top Wages. The first variable captures the impact of the UI extension on the low-wages group, whereas the other variables 
identify the impact on each of the remaining wage groups relatively to the first. The main conclusion to be drawn from the results is that the level of pre-unemployment wages entails different reactions to the same policy incentive, which confirms the model prediction. The three point estimates are statistically different from zero, which makes the impact significant and the reaction of the low-wages group different from each of the other two wage groups. Additionally, a Wald test rejects the equality of the coefficients of the interquartile and top quartile groups (a statistic of 4.97 , which has a $p$-value of 0.0258 in the $\chi_{1}^{2}$ distribution). The estimates imply a reduction in the unemployment hazard of 26 percentage points for workers in the first quartile of average pre-unemployment wages. Relatively to these workers, the reduction is 20 percentage points larger for an average worker in the interquartile range and 11 percentage points larger for those in the top quartile. The evidence collected results in a hump-shaped (concave) response to the benefit extension with respect to the ability of smooth consumption as proxied by the accumulated pre-unemployment wages distribution.

What can account for this non-monotonic pattern? As seen in the theoretical section, the reaction to an UI extension works through both the consumption and the survival channels, which affect unemployment duration differently. To explore the importance of the survival channel, we use the data from the pre-reform period, to avoid endogeneity issues, and compute unemployment survival rates by level of accumulated pre-unemployment wages. Figure 4 plots Cox-proportional baseline survival rates. The estimates suggest that the conditional probability of remaining unemployed increases with the pre-unemployment wage. This is particularly true when we compare the behavior of individuals in the lowest quartile of accumulated wages with those in the other quartiles. For example, the probability of remaining unemployed after one year of joblessness is more than two times larger for an individual in the top quartile than for an individual in the bottom quartile. This type of relationship corroborates the results of Bloemen \& Stancanelli (2001) and Algan et al. (2003).

[FIGURE 4; see page 28]

We can use these unemployment survival rates to help interpreting the hump shape pattern in the results. First, consider the interquartile and the top quartile groups that have virtually the same unemployment survival probability at all durations. For these two groups, the difference in the impacts is defined by the consumption channel. As expected, workers with interquartile wages react more to the incentive due to their larger marginal utility of consumption. This result 
is consistent with the evidence of a liquidity effect of UI reported in Chetty (2008) and Card et al. (2007a). Next, consider the lowest quartile group, the one with the smallest probability of exhausting benefits. Given that these are the individuals with the lowest income, by the consumption channel, they should have had the largest reaction. However, the lowest survival probability mitigates the consumption channel effect to the point where the overall impact is the smallest of all these groups.

The consumption channel is mainly driven by wages, but it is conceivable that the survival channel depends more generally on the individual's labor market prospects. A key variable to account for these prospects is the job offers arrival rate. What is the impact of not having this variable in our regression? Consider the case of low-wage workers. These workers have low qualifications, a low payoff to long search periods, and may not afford such long periods. Furthermore, they also have a large pool of low-wage job offers to find a match, resulting in short unemployment durations (Addison, Centeno \& Portugal 2009). Therefore, the wage indicator and the job offers arrival rate have the same association with unemployment duration. A similar argument applies to the high-wage workers. They face a lower arrival rate of job offers, have an option value to search longer, and can afford it. So the impact of labor market prospects on the search behavior of high-wage workers will lead to longer unemployment duration, precisely the association obtained with the high-wage dummies. Overall, although we cannot interpret the coefficients on the wage dummies as causal of the effect of wages, the omission of the job offers arrival rates does not affect the inferred qualitative behavior across unconstrained and constrained individuals.

To show that our results do not depend on the assumption of a common baseline across such potentially heterogeneous groups, we reestimate the fully-flexible model described in equation (4). Now, the groups are stratified over the triplet defined by the two treatment status, the two periods and the three wage groups. Figure 5 plots the corresponding difference-in-differences treatment effects on the survival rates for each of the three wage groups. It is clear that the imposition of a common baseline in equation (5) does not drive the results presented in Table 4. After the 4th month of subsidized unemployment, the low-wage has the smallest shift in the survival curve, followed by the top quartile. As before, the largest impact occurs always in the interquartile wage group.

[FIGURE 5; see page 29] 
Chetty (2008) takes as evidence in favor of the liquidity effect the fact that liquidity constrained individuals react more to an increase in the replacement rate. This result stresses the impact of UI on the marginal utility of consumption. In the case of an UI extension, the more constrained reacted the least. Does this question the liquidity effect? We believe that it does not, but instead clarifies how the liquidity effect arises in UI extensions. Poorer individuals are financially less capable of postponing reemployment and, therefore, benefit less from an extension that occurs at a distant period in time; larger replacement rates are more likely to potentiate the liquidity effect among these unemployed workers.

\subsection{Robustness}

We now check the robustness of our results. First, we exclude from the analysis individuals aged 34 or 35 years, who may have self-selected into UI due to the longer entitlement periods. Second, we study the impact on an older treatment group, specifically those aged 40 to 44 . Then, we consider a falsification test by taking the age group [25, 29], whose entitlement period did not change, as a placebo treatment group. Finally, we scrutinize the sensitivity of our findings to two potential biases coming from anticipation effects and changes in the business cycle.

\section{Excluding 34- and 35-year-old unemployed}

In the before period, claiming benefits at age 35 was more attractive than at age 34 . In order to benefit from 3 additional months of coverage, it is plausible that some individuals postponed UI claims until they were aged 35 . In order to control for this potential self-selection, we exclude from the analysis all individuals aged 35, but also those aged 34, who may be a selection due to the behavior of some individuals in the 35-year group. We also consider excluding from the analysis only 35-year-old individuals. The results are presented in columns (1) and (2) of Table 5 , respectively.

[TABLE 5; see page 26]

The point estimates of the treatment effect by wage level are robust. The impact of the reform for low-wage individuals is slightly smaller than in the benchmark estimate and slightly larger for the other two groups. These changes do not affect the ranking of the impacts, resulting still in the hump-shaped reaction to longer UI benefits. 


\section{Treatment group: $[40,44]$}

The age group $[40,44]$ can be considered as an alternative treatment group because its entitlement period increased from 21 to 24 months. Again, the contiguous age group, [35, 39], plays the role of the control group with 18 months of benefits. However, neither before, nor after the reform do these groups share the same entitlement period. Remarkably, the ranking of the point estimates by pre-unemployment wage levels is preserved for the $[40,44]$ treatment group (Table 5). The point estimates are in the range of those obtained for the prime-age treatment group, $[30,34]$, but the estimates refer now to changes in the hazard rate in the first 540 days of subsidized unemployment. Also, the fully-flexible approach yields difference-in-differences estimates plotted in the left-hand side of Figure 6 that resemble those in Figure 5.

[FIGURE 6; see page 29]

\section{Falsification test}

We use as a placebo treatment group individuals aged $[25,29]$ to construct a falsification test. This group has a 12-month entitlement period throughout the analysis period, while the control group, still the $[35,39]$ age group, has an 18-month entitlement period. Thus, neither group benefits from an extension of the entitlement. The results are reassuring of the appropriateness of our identification strategy (Table 5 and right panel of Figure 6). We did not find significant differences in the before and after periods for the placebo treatment and control groups. The only exception seems to be for those in the top quartile. Nonetheless, the impact on the survival rate for the latter group is only 4.1 percentage points, much smaller than the range of impacts estimated before. We should stress, however, that the age, experience, and tenure differences between these two age groups may make it harder to find a common support of accumulated pre-unemployment wages. This is particularly the case at the upper tail of the distribution, where the Mincerian income profile for the age range considered (25 to 39 years) is quite steep. Thus, we consider that these results are reassuring, but should be interpreted more cautiously.

\section{Anticipation effects}

As it is the case with most legislative reforms, there is the possibility of some kind of anticipation effect (the so called Ashenfelter's dip). Self-selection may arise because some individuals may have delayed unemployment to enter the new UI regime. Arguably, these are individuals 
that have higher expected unemployment durations, insuring themselves with the entitlement extension. Thus, it is possible that, around the enactment of the new law, the duration of subsidized unemployment could be biased as a result of the self-selection. To address this issue, we excluded from the sample all individuals that claimed benefits during the 6-month time window centered around July, 1999, i.e., between April 1 and September 30, 1999.

The results based on the fully-flexible baseline approach plotted in the left panel of Figure 7 show a high similarity with the results discussed hitherto, which suggests that they are not driven by the existence of anticipation effects.

[FIGURE 7; see page 30]

\section{Macroeconomic cycle}

Finally, we consider also an alternative definition of the after period, namely, July, 1999 to December, 2000. This choice yields a more uniform macroeconomic cycle, avoiding the possible pitfalls associated with changes in the business cycle that affect, in a differentiated way, the younger (treatment) and older (control) groups. The same conclusion is reached with this exercise; the ranking of the curves is preserved, right panel of Figure 7, but the impacts at the interquartile and top quartile subsamples are slightly closer, with the gap to the bottom quartile widening.

The several robustness check performed are reassuring that our results are invariant to age groups, self-selection issues, and macroeconomic conditions.

\section{Conclusions}

We investigate the heterogeneous impact on subsidized unemployment duration of an UI extension when the unemployed have different levels of accumulated pre-unemployment wages. The empirical exercise explores a quasi-experimental setting generated by a reform of the Portuguese UI system that affected only certain age groups.

We observe a strong reaction to the policy change, consistent with a forward looking behavior of the unemployed. The novelty of our approach rests on the evidence that there is a humpshape elasticity of unemployment duration relatively to accumulated pre-unemployment wages; individuals at the bottom and at the top of the accumulated wages distribution reacted less 
than those in the interquartile range. In light of the model in Card et al. (2007a), this result is consistent with an important impact of savings on the use of UI.

This characterization of the individual search behavior provides important insights towards designing an optimal UI policy. The fact that low-wage workers, those more likely to be unable to smooth temporary income fluctuations, reacted less to a benefit extension questions the ability of long benefits to fulfill the social insurance goal. In particular, we conclude that it is harder to potentiate the non-distortionary liquidity effect with extensions of already quite long benefits. This points towards the promotion of insurance policies such as cash-on-hand or with higher benefits accruing early in the unemployment spell. 


\section{References}

Addison, J., Centeno, M. \& Portugal, J. (2009), 'Do reservation wages really decline? Some international evidence on the determinants of reservation wages', Journal of Labor Research 30, 1-8.

Addison, J., Centeno, M. \& Portugal, J. (2010), 'Unemployment benefits and reservation wages: Key elasticities from a stripped-down job search approach', Economica 77, 46-59.

Addison, J. \& Portugal, J. (2008), 'How do different entitlements to unemployment benefits affect the transitions from unemployment into employment?', Economics Letters 101(3), 206209.

Algan, Y., Chéron, A., Hairault, J. \& Langot, F. (2003), 'Wealth effect on labor market transitions', Review of Economic Dynamics 6(1), 156-178.

Angrist, J. D. \& Pischke, J.-S. (2009), Mostly Harmless Econometrics: An Empiricist's Companion, Princeton University Press.

Bloemen, H. \& Stancanelli, E. (2001), 'Individual wealth, reservation wages, and transitions into employment', Journal of Labor Economics 19(2), 400-439.

Card, D., Chetty, R. \& Weber, A. (2007a), 'Cash-on-hand and competing models of intertemporal behavior: New evidence from the labor market', Quarterly Journal of Economics 122(4), 1511-1560.

Card, D., Chetty, R. \& Weber, A. (2007b), 'The spike at benefit exhaustion: Leaving the unemployment system or starting a new job?', American Economic Review 97(2), 113-118.

Card, D. \& Levine, P. B. (2000), 'Extended benefits and the duration of UI spells: Evidence from the New Jersey extended benefit program', Journal of Public Economics 78, 107-138.

Chetty, R. (2008), 'Moral hazard versus liquidity and optimal unemployment insurance', Journal of Political Economy 116(2), 173-234.

Cox, D. R. (1972), 'Regression models and life-tables', Journal of the Royal Statistical Society Series B(34), 187-220.

Fitzenberger, B. \& Wilke, R. (2010), 'New insights into unemployment duration and post unemployment earnings in Germany', Oxford Bulletin of Economics and Statistics 72(6), 794-826. 
Gruber, J. (1997), 'The consumption smoothing benefits of unemployment insurance', American Economic Review 87(1), 192-205.

Hunt, J. (1995), 'The effect of unemployment compensation on unemployment duration in Germany', Journal of Labor Economics 13(1), 88-120.

Kalbfleisch, J. \& Prentice, R. (2002), The Statistical Analysis of Failure Time Data, Wiley Interscience.

Kyyra, T. \& Wilke, R. (2007), 'Reduction in the long-term unemployment of the elderly: A success story from Finland revisited', Journal of the European Economic Association 5(1), 154182.

Lalive, R., van Ours, J. C. \& Zweimueller, J. (2006), 'How changes in financial incentives affect the duration of unemployment', Review of Economic Studies 73, 1009-1038.

Lancaster, T. (1992), The Econometric Analysis of Transition Data, Cambridge University Press, Cambridge.

Lentz, R. \& Tranæs, T. (2005), 'Job search and savings: Wealth effects and duration dependence', Journal of Labor Economics 23(3), 467-489.

Mortensen, D. (1986), Job search and labor market analysis, in O. Ashenfelter \& R. Layard, eds, 'Handbook of Labor Economics', Vol. 2, North-Holland, Amsterdam, pp. 849-919.

Narendranathan, W., Nickell, S. \& Stern, J. (1985), 'Unemployment benefits revisited', The Economic Journal 95(378), 307-329.

Stancanelli, E. (1999), 'Do the rich stay unemployed longer? An empirical study for the UK', Oxford Bulletin of Economics and Statistics 61(3), 295-314.

van Ours, J. C. \& Vodopivec, M. (2006), 'How changes in benefits entitlement affect job-finding: Lessons from the Slovenian "experiment"', Journal of Labor Economics 24(2), 351-378.

Ziliak, J. P. (2003), 'Income transfers and assets of the poor', Review of Economics and Statistics $\mathbf{8 5}(1), 63-76$. 
Table 1: Entitlement periods (in months): Before and after July, 1999

\begin{tabular}{|c|c|c|c|}
\hline \multicolumn{2}{|r|}{ Before } & \multicolumn{2}{|r|}{ After } \\
\hline Age (years) $\dagger$ & Entitlement period & Age (years) $\dagger$ & Entitlement period \\
\hline$[15,24]$ & 10 & {$\left[\begin{array}{ll}1 & 20\end{array}\right]$} & 12 \\
\hline$[25,29]$ & 12 & {$[15,29]$} & 12 \\
\hline$[30,34]$ & 15 & {$\left[\begin{array}{lll}30 & 30\end{array}\right]$} & 18 \\
\hline$[35,39]$ & 18 & {$[30,39]$} & 18 \\
\hline$[40,44]$ & 21 & {$[40,44]$} & 24 \\
\hline$[45,49]$ & 24 & & \\
\hline$[50,54]$ & 27 & {$[45,64]$} & $30(+8)^{*}$ \\
\hline$[55,64]$ & 30 & & \\
\hline
\end{tabular}

Table 2: The Portuguese economy before and after July 1999

\begin{tabular}{cccccc}
\hline & $\begin{array}{c}\text { Real GDP } \\
\text { Growth }^{(1)}\end{array}$ & $\begin{array}{c}\text { Employment } \\
\text { Growth }^{(2)}\end{array}$ & $\begin{array}{c}\text { Unemployment }^{\text {Rate }^{(2)}} \\
\text { Unemployment (\%) }\end{array}$ & $\begin{array}{c}\text { Long-term } \\
\text { Subsidized } \\
\text { Unemployed } \\
\text { thousands) }^{(3)}\end{array}$ \\
\hline 1997 & 4.2 & 1.9 & 5.8 & 43.6 & 172.9 \\
1998 & 4.7 & 2.3 & 5.0 & 45.4 & 165.1 \\
1999 & 3.9 & 1.9 & 4.4 & 41.2 & 163.1 \\
2000 & 3.9 & 2.3 & 3.9 & 43.8 & 166.6 \\
2001 & 2.0 & 1.5 & 4.0 & 40.0 & 176.1 \\
2002 & 0.8 & 0.5 & 5.0 & 37.3 & 195.2 \\
2003 & -1.2 & -0.4 & 6.3 & 37.7 & 248.2 \\
2004 & 1.1 & 0.1 & 6.7 & 46.2 & 288.4 \\
\hline
\end{tabular}

Sources: (1) National accounts, INE; (2) Employment Survey, INE; (3) Social Security Bureau, MTSS. 
Table 3: Summary statistics: Mean values by treatment status and period

\begin{tabular}{lrrrr}
\hline & \multicolumn{2}{c}{ Before } & \multicolumn{2}{c}{ After } \\
Variables & Treatment & Control & Treatment & Control \\
\hline Subsidized unemployment spell (days) & 202.16 & 301.25 & 275.09 & 294.76 \\
Spells ending in reemployment (\%) & 98.7 & 94.6 & 84.8 & 81.3 \\
Age at the beginning of the spell & 31.92 & 36.93 & 31.86 & 36.89 \\
Female & 0.42 & 0.40 & 0.55 & 0.51 \\
Pre-unemployment wages (1999 euros) & 593.30 & 680.58 & 647.71 & 662.06 \\
Gross replacement ratio & 69.07 & 67.48 & 69.73 & 69.76 \\
Month of unemployment entry & & & & \\
January & 0.17 & 0.14 & 0.12 & 0.12 \\
February & 0.12 & 0.12 & 0.08 & 0.09 \\
March & 0.11 & 0.11 & 0.09 & 0.09 \\
April & 0.11 & 0.12 & 0.08 & 0.09 \\
May & 0.10 & 0.10 & 0.09 & 0.09 \\
June & 0.09 & 0.09 & 0.08 & 0.09 \\
July & 0.05 & 0.05 & 0.07 & 0.07 \\
August & 0.05 & 0.05 & 0.06 & 0.06 \\
September & 0.05 & 0.04 & 0.13 & 0.10 \\
October & 0.05 & 0.06 & 0.07 & 0.08 \\
November & 0.05 & 0.06 & 0.07 & 0.07 \\
December & 0.04 & 0.05 & 0.06 & 0.06 \\
No. of observations & & & & \\
\hline Notes: & 4,780 & 5,160 & 30,173 & 22,434 \\
\hline
\end{tabular}

Notes: (1) Period: January, 1998 through June 2003. The before period covers spells initiated between January, 1998 and June, 1999; the after period covers spells initiated between July, 1999 and June, 2003; (2) Treatment group: Composed of unemployed aged 30 to 34 years at the beginning of the unemployment spell. Their entitlement period increases from 15 months in the before period to 18 months in the after period; (3) Control group: Composed of unemployed aged 35 to 39 years at the beginning of the unemployment spell. Their entitlement period remains at 18 months in both periods; (4) Subsidized unemployment spells: The durations reported correspond to complete spells. All transitions out of unemployment are considered; (5) Wages: Reported values correspond to a 12-month average of pre-unemployment wages; (6) Gross replacement rate (GRR): The benefits paid vary with the unemployed's pre-unemployment average wages. Briefly, for those who earned between 1 and 1.5 minimum wages per month, the monthly benefits paid correspond to one minimum wage; those who earned between 1.5 and 4.5 minimum wages, the GRR is set at 65 percent; the benefits are capped at 3 minimum wages for those who earned more than 4.5 minimum wages per month. Source: II's dataset; authors computations. 
Table 4: Cox proportional hazard model estimates

\begin{tabular}{|c|c|c|c|}
\hline Subsidized unemployment spell (days) & $(1)$ & $(2)$ & $(3)$ \\
\hline \multirow{2}{*}{ After } & 0.053 & 0.029 & 0.039 \\
\hline & $(2.75)$ & $(1.53)$ & $(1.13)$ \\
\hline \multirow[t]{2}{*}{ Treat } & 0.424 & 0.399 & 0.142 \\
\hline & $(14.93)$ & $(14.03)$ & $(3.25)$ \\
\hline \multirow{2}{*}{ After $\times$ Treat } & -0.492 & -0.463 & -0.303 \\
\hline & $(-19.54)$ & $(-18.37)$ & $(-6.70)$ \\
\hline \multicolumn{2}{|l|}{ After $\times$ Treat $\times$ Interquartile Wages } & & $\begin{array}{l}-0.315 \\
(-5.48)\end{array}$ \\
\hline \multicolumn{2}{|l|}{ After $\times$ Treat $\times$ Top Wages } & & $\begin{array}{l}-0.164 \\
(-2.22)\end{array}$ \\
\hline Interquartile range Wages & & $\begin{array}{r}-0.558 \\
(-37.80)\end{array}$ & $\begin{array}{r}-0.665 \\
(-16.46)\end{array}$ \\
\hline Top Quartile Wages & & $\begin{array}{r}-0.696 \\
(-35.40)\end{array}$ & $\begin{array}{r}-0.855 \\
(-16.52)\end{array}$ \\
\hline Treat $\times$ Interquartile Wages & & & $\begin{array}{r}0.364 \\
(7.04)\end{array}$ \\
\hline Treat $\times$ Top Wages & & & $\begin{array}{r}0.487 \\
(7.25)\end{array}$ \\
\hline After $\times$ Interquartile Wages & & & $\begin{array}{r}0.031 \\
(0.71)\end{array}$ \\
\hline After $\times$ Top Wages & & & $\begin{array}{l}-0.092 \\
(-1.68)\end{array}$ \\
\hline Other variables & Yes & Yes & Yes \\
\hline No of observations & 62,547 & 62,547 & 62,547 \\
\hline
\end{tabular}

Notes: (1) Subsidized unemployment durations are censored at 450 days, which is the common entitlement period for the treatment and control groups in both periods. The coefficients can be interpreted as changes in the subsidized unemployment hazard rate over the first 450 days of the spell; (2) Treat: Binary variable that identifies treated individuals, those aged 30 to 34 years. In the After period, treated are entitled to 18 months of benefits, in the before period the entitlement was 15 months. The control group is composed of individuals aged 35 to 39 years with entitlement periods of 18 months; (3) 'Interquartile wages' is an indicator variable for individuals with average pre-unemployment wages in the interquartile range; 'Top wages' is an indicator for individuals with top quartile average pre-unemployment wages. (4) The list of 'Other variables' includes: female indicator; age (demeaned); month of unemployment entry and regional dummies; gross replacement rate (demeaned); and, in the case of column (1), the log of the 12 -month average of pre-unemployment wages (demeaned). (5) Cox proportional hazard model with common baseline function (see equation (5)); $t$-statistics in parentheses. 
Table 5: Cox proportional hazard model estimates: Robustness checks

\begin{tabular}{|c|c|c|c|c|}
\hline \multirow[b]{2}{*}{ Subsidized unemployment spell (days) } & \multicolumn{2}{|c|}{ Excluding: } & \multirow{2}{*}{$\begin{array}{c}\text { Treatment } \\
{[40,44]}\end{array}$} & \multirow{2}{*}{$\begin{array}{c}\text { Falsification } \\
{[25,29] ;[35,39]}\end{array}$} \\
\hline & $34 \& 35$ & 35 & & \\
\hline \multirow[t]{2}{*}{ After } & 0.006 & 0.006 & 0.053 & 0.027 \\
\hline & $(0.16)$ & $(0.15)$ & $(1.56)$ & $(0.75)$ \\
\hline \multirow[t]{2}{*}{ Treat } & 0.064 & 0.104 & 0.261 & -0.117 \\
\hline & $(1.26)$ & $(2.16)$ & $(5.27)$ & $(-2.32)$ \\
\hline \multirow[t]{2}{*}{ After $\times$ Treat } & -0.241 & -0.270 & -0.498 & -0.001 \\
\hline & $(-4.78)$ & $(-5.56)$ & $(-9.73)$ & $(-0.03)$ \\
\hline \multirow[t]{2}{*}{ After $\times$ Treat $\times$ Interquartile Wages } & -0.349 & -0.341 & -0.136 & -0.070 \\
\hline & $(-5.49)$ & $(-5.54)$ & $(-2.12)$ & $(-1.24)$ \\
\hline \multirow[t]{2}{*}{ After $\times$ Treat $\times$ Top Wages } & -0.214 & -0.192 & -0.155 & 0.317 \\
\hline & $(-2.62)$ & $(-2.47)$ & $(-1.95)$ & $(4.08)$ \\
\hline \multirow[t]{2}{*}{ Interquartile range Wages } & -0.684 & -0.689 & -0.643 & -0.727 \\
\hline & $(-14.85)$ & $(-14.98)$ & $(-16.58)$ & $(-17.02)$ \\
\hline \multirow[t]{2}{*}{ Top Wages } & -0.872 & -0.880 & -0.854 & -0.916 \\
\hline & $(-15.04)$ & $(-15.19)$ & $(-17.31)$ & $(-16.65)$ \\
\hline \multirow[t]{2}{*}{ Treat $\times$ Interquartile Wages } & 0.397 & 0.390 & 0.095 & 0.312 \\
\hline & $(6.81)$ & $(6.94)$ & $(1.64)$ & $(6.13)$ \\
\hline \multirow[t]{2}{*}{ Treat $\times$ Top Wages } & 0.535 & 0.515 & 0.076 & 0.384 \\
\hline & $(7.07)$ & $(7.15)$ & $(1.05)$ & $(5.32)$ \\
\hline \multirow[t]{2}{*}{ After $\times$ Interquartile Wages } & 0.056 & 0.057 & 0.018 & 0.038 \\
\hline & $(1.15)$ & $(1.17)$ & $(0.42)$ & $(0.83)$ \\
\hline \multirow[t]{2}{*}{ After $\times$ Top Wages } & -0.065 & -0.064 & -0.111 & -0.100 \\
\hline & $(-1.08)$ & $(-1.05)$ & $(-2.14)$ & $(-1.72)$ \\
\hline Other variables & Yes & Yes & Yes & Yes \\
\hline No of observations & 60,543 & 61,427 & 50,617 & 71,379 \\
\hline
\end{tabular}

Notes: (1) Excluding "34 \& 35" and "35": In the before period, due to the longer entitlement of individuals aged 35-39 years, it is plausible that unemployed workers aged 34 and 35 claimed UI strategically to benefit from the longer coverage. In these regressions, we exclude individuals aged 34 or 35 at the beginning of their unemployment spell. The point estimates can be compared with column (3) of Table 4; (2) Treatment [40,44]: Treatment group includes unemployed aged 40 to 44 years. The control group is the age group 35-39. The entitlement period increased from 21 to 24 months for the treatment group, but remained unchanged at 18 months for the control group. Subsidized unemployment durations are censored at 540 days, which is the common entitlement period for the treatment and control groups in both periods. (3) Falsification: Treatment group is composed of pseudo-treated individuals aged 25 to 29 years. For these individuals the entitlement period remained unchanged at 12 months throughout the analysis period. The control group is again the age group 35-39; Durations are censored at 360 days, which is the common entitlement period for the pseudo-treatment and control groups. (4) 'Interquartile wages' is an indicator variable for individuals with average pre-unemployment wages in the interquartile range; 'Top wages' is an indicator for individuals with top quartile average pre-unemployment wages. (5) The list of 'Other variables' includes: female indicator; age; month of unemployment entry and regional dummies; gross replacement rate; (6) Cox proportional hazard model with common baseline function (see equation (5)); $t$-statistics in parentheses. 

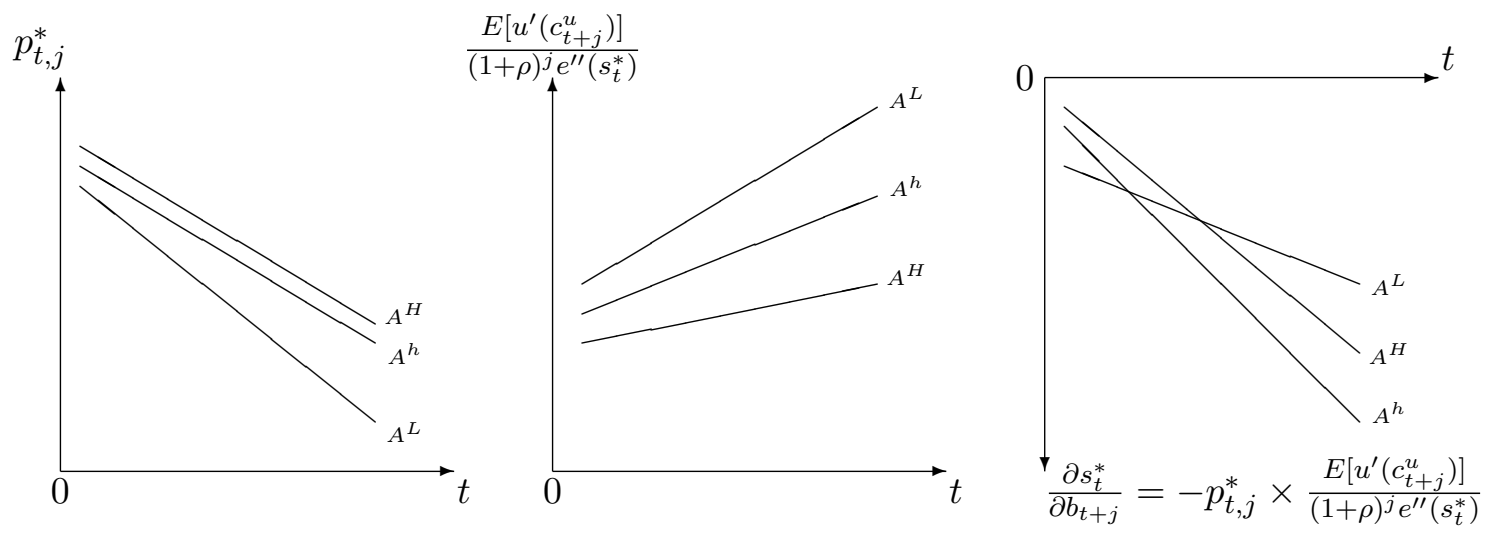

Figure 1: Decomposition of the marginal impact of an extension of the UI entitlement period on job search intensity, $s^{*}$. The three curves in each plot represent levels of assets: high, $A^{H}$; intermediate, $A^{h}$; and low, $A^{L}$. The left plot depicts the unemployment survival channel, $p_{t, j}^{*}$. Unconstrained individuals, $A^{H}$, stay unemployed longer. The middle plot shows the consumption channel. Its effect is stronger for constrained individuals, $A^{L}$. As the unemployment spell progresses, unemployed workers become financially more constrained and, therefore, the marginal utility of consumption increases. Finally, the last plot shows the total effect on the exit rate from unemployment (search intensity), which is the (symmetric of the) product of the two channels. It shows one possible instance where the financially constrained workers, $A^{L}$, react the least at longer spells due to the survival channel and where those with an intermediate level of assets, $A^{h}$, react the most.

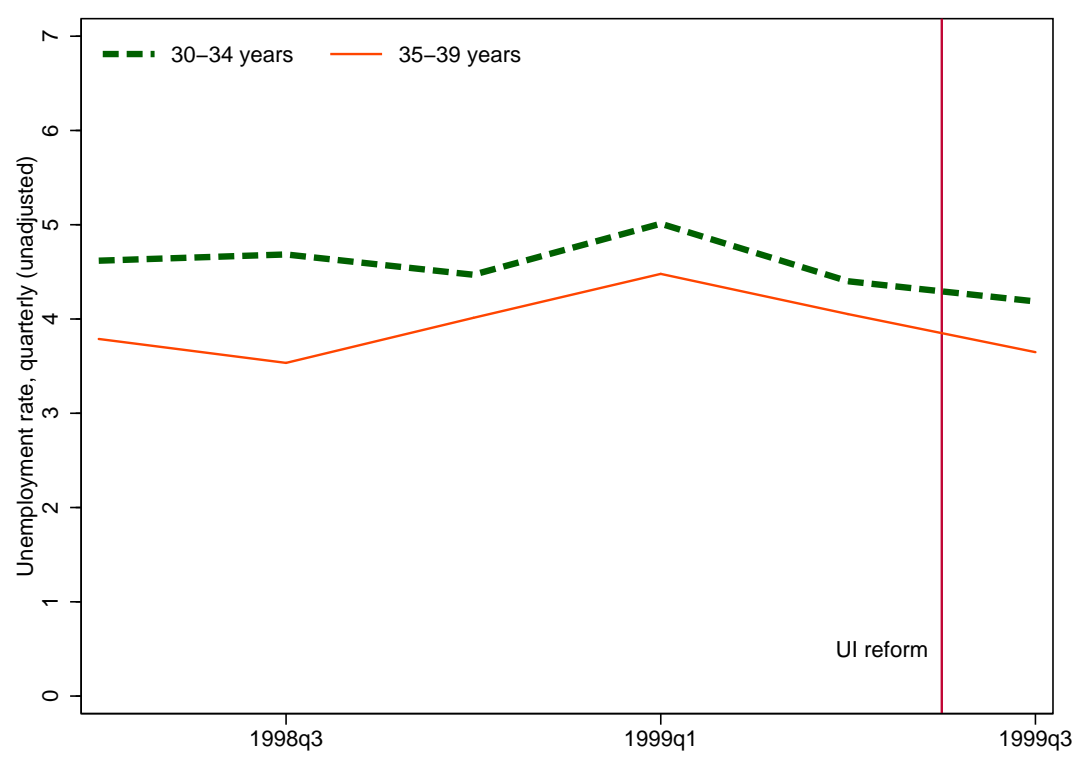

Figure 2: Seasonally unadjusted quarterly unemployment rate by age groups. Source: Portuguese labor force survey (Inquérito ao Emprego); authors' computations 


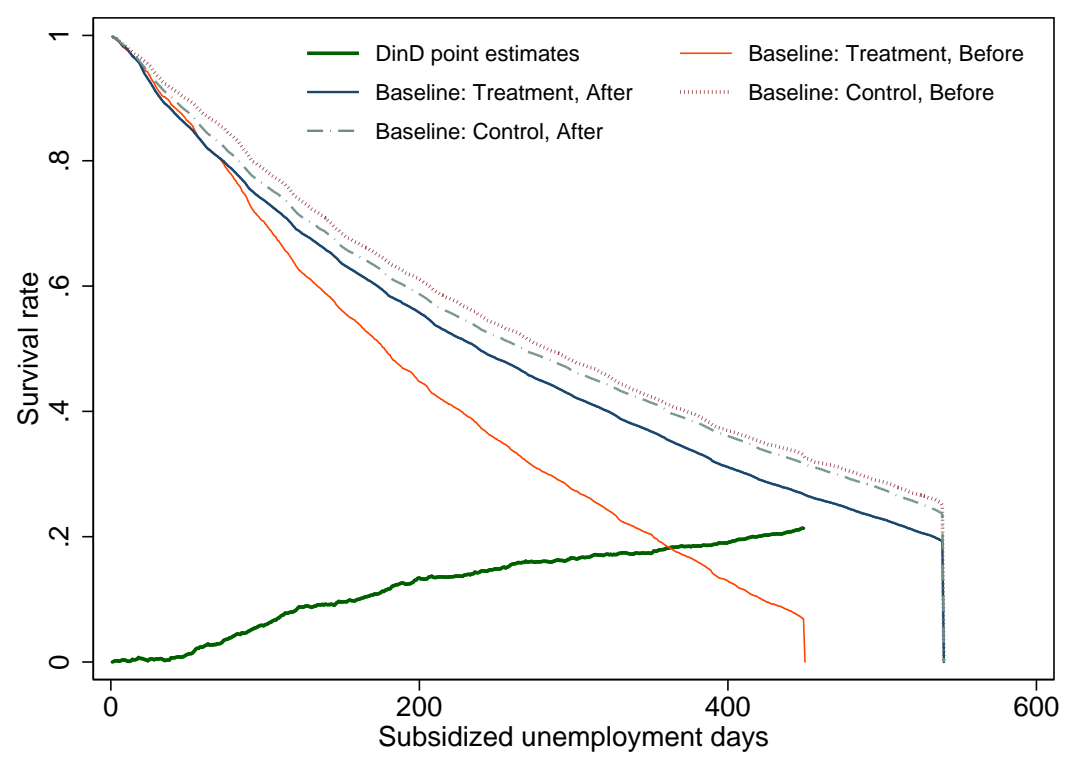

Figure 3: Cox proportional model estimates: Fully-flexible baseline survival curves defined over pairs of treatment status (control and treatment) and period (before and after). All covariates are evaluated at their sample means, except dummy variables, which are evaluated at zero. The difference-in-differences treatment effect estimates (bottom curve) are obtained by taking the appropriate differences between the baseline curves, namely, \{Baseline: Treatment, After - Baseline: Treatment, Before $\}-\{$ Baseline: Control, After - Baseline: Control, Before $\}$

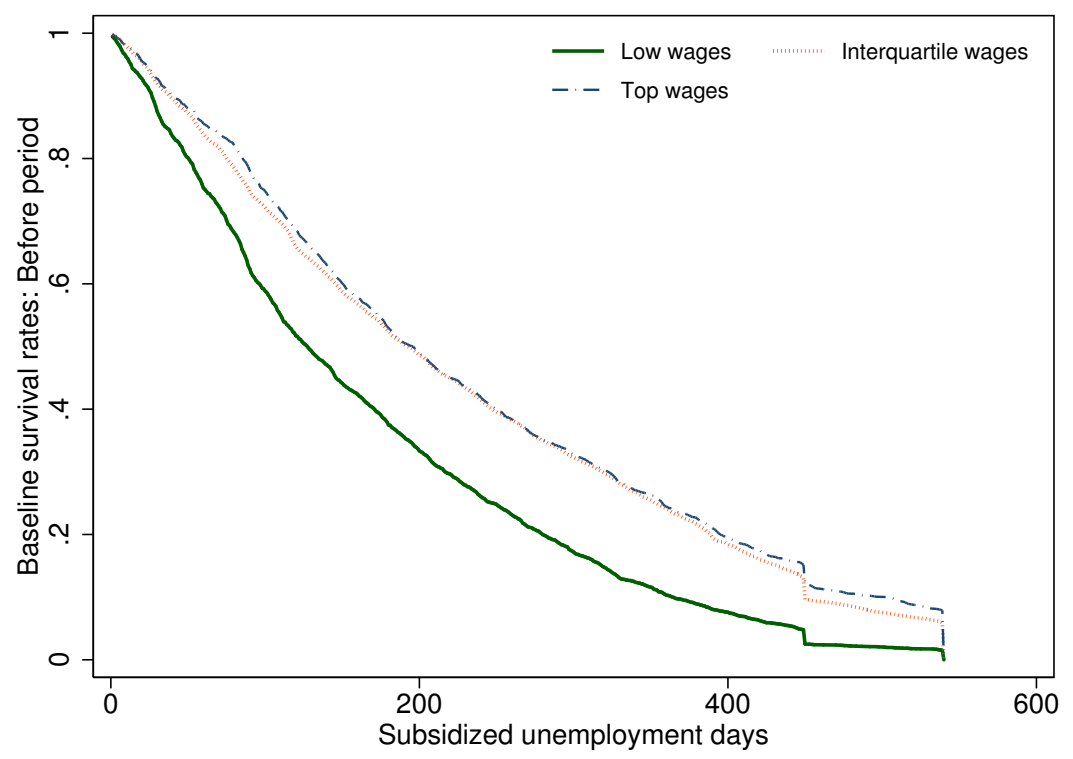

Figure 4: Cox proportional baseline survival curves by wage level: All covariates are evaluated at their sample means, except dummy variables, which are evaluated at zero. Estimates for the period before the reform, January 1998-June, 1999. Includes all individuals aged 30-39. The first accentuated fall in the survival rate, at 450 days (15 months), coincides with the end of the entitlement period for those aged 30-34, and the final one, at 540 days (18 months) with the end of the entitlement period for the older individuals. 


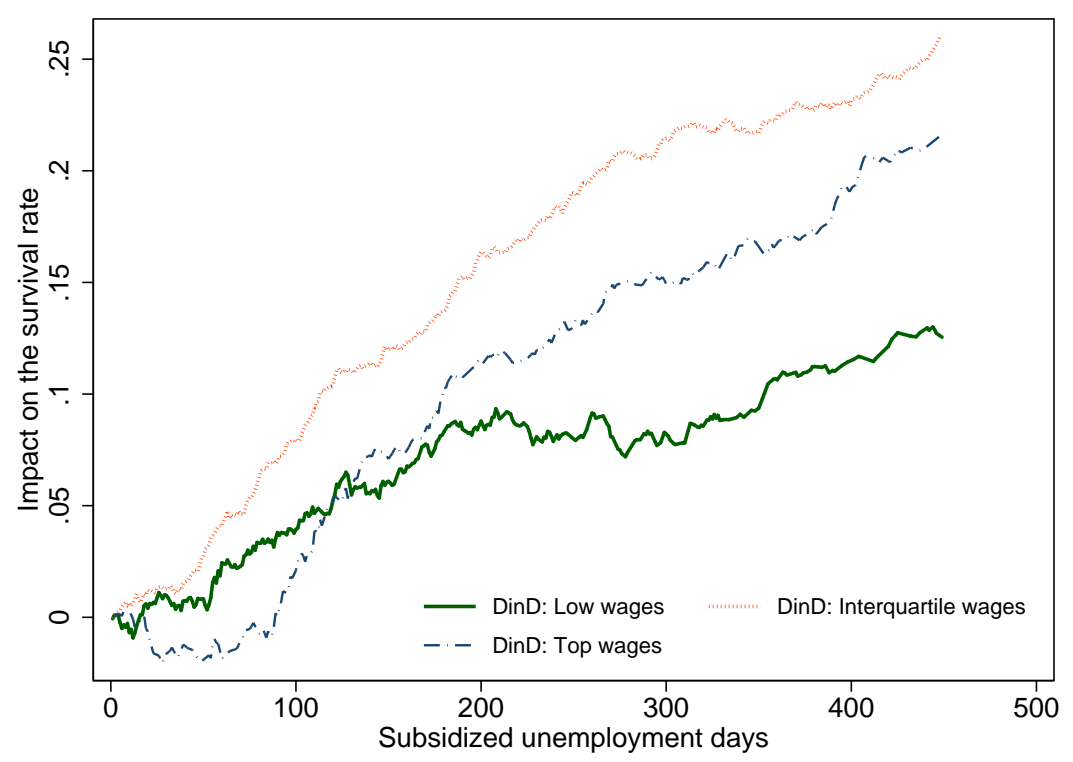

Figure 5: Difference-in-differences by pre-unemployment wage group: Treatment effect estimates derived from estimates of fully-flexible baseline survival curves of a Cox proportional model. Each baseline is defined over the triplet of two treatment status, two periods, and three wage group. All covariates are evaluated at their sample means, except dummy variables, which are evaluated at zero. For each wage group, the difference-in-differences treatment effect estimates are obtained with the standard procedure described in Figure 3.
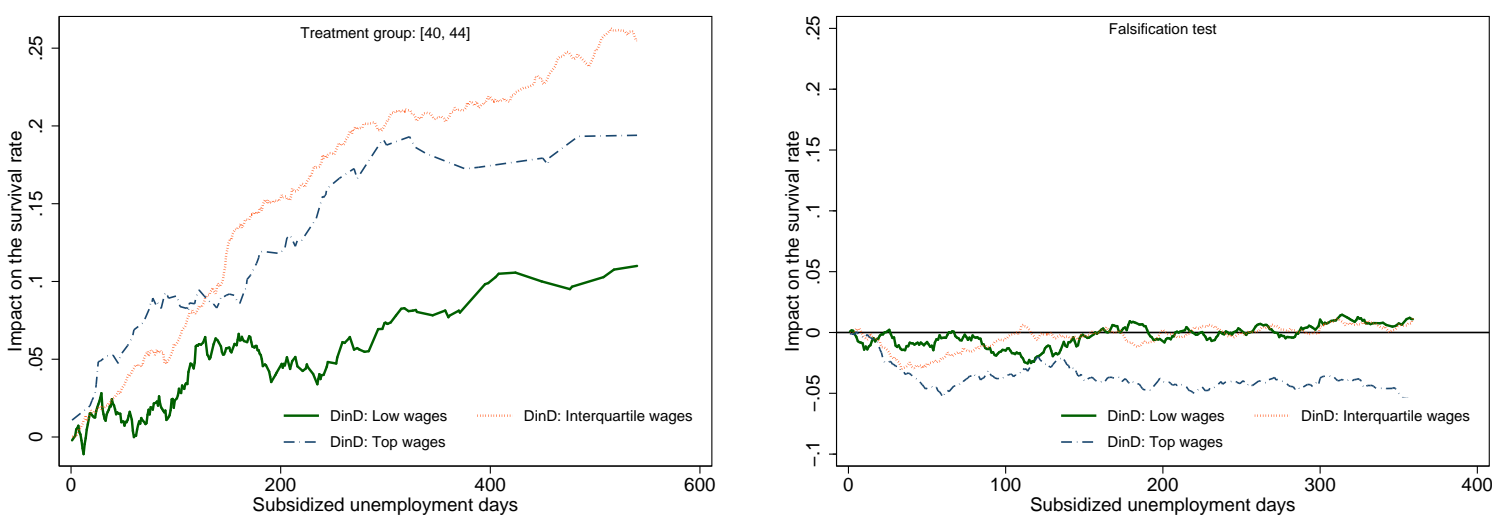

Figure 6: Difference-in-differences: Treatment effect estimates derived from Cox proportional model fully-flexible baseline survival curves (similar construction to the estimates presented and described in Figures 3 and 5). The left panel presents the impact on the 40-44 treatment group. The right panel presents the falsification test, assuming that the treated individuals are those aged 25-29. 

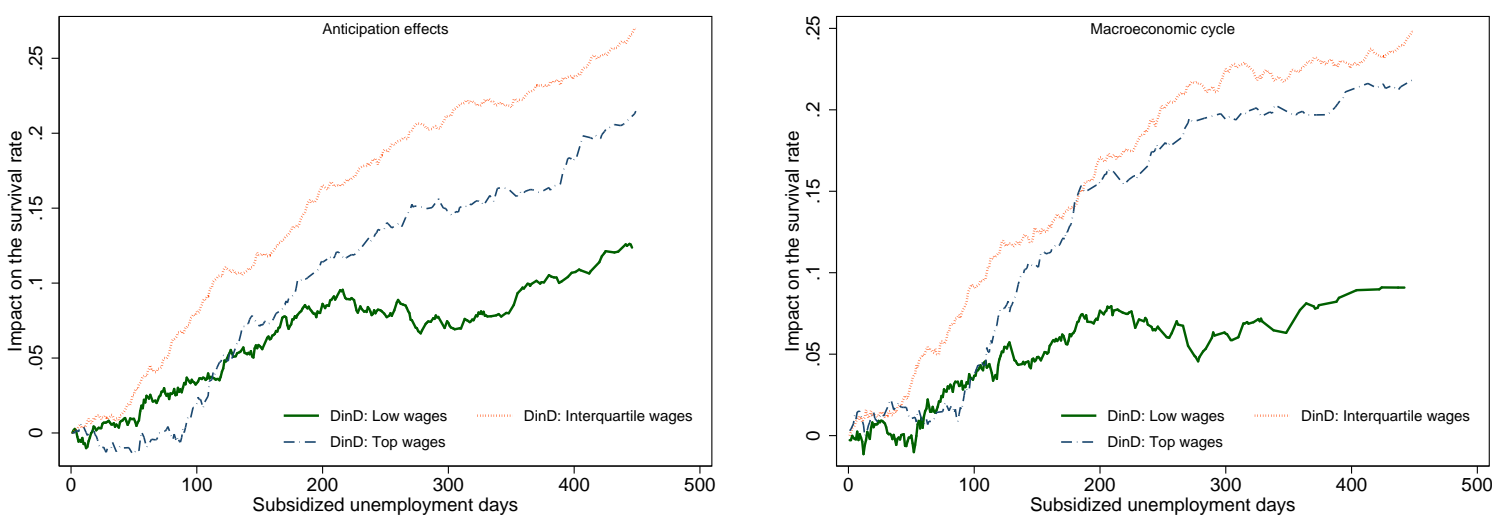

Figure 7: Difference-in-differences: Treatment effect estimates derived from Cox proportional model fully-flexible baseline survival curves (similar construction to the estimates presented and described in Figures 3 and 5). The left-panel addresses the possibility of anticipation effects by excluding from the sample individuals enrolled 3 months before and after the reform implementation. The right-panel addresses the macroeconomic cycle. The before period (January, 1998 to June, 1999) and the after period (July, 1999 to December, 2000) have rather similar positions in the business cycle (see Table 2). 